\title{
Second-Generation Antipsychotic Drugs for Patients with Schizophrenia: Systematic Literature Review and Meta-analysis of Metabolic and Cardiovascular Side Effects
}

\author{
Carla Rognoni $^{1}$ [D $\cdot$ Arianna Bertolani ${ }^{1} \cdot$ Claudio Jommi $^{1}$
}

Accepted: 15 January 2021

(c) The Author(s) 2021, corrected publication 2021

\begin{abstract}
Background and Objectives Second-generation antipsychotics (SGAs) for schizophrenia show different risk profiles, whose evidence has been evaluated through comparative reviews on randomized controlled trials (RCTs) and observational studies. Methods We performed a systematic review and meta-analysis of weight gains, metabolic and cardiovascular side effects of SGAs, relying on both RCTs and observational studies, by comparing variations between the start of treatment and the end of follow-up. The systematic review refers to papers published from June 2009 to November 2020. PRISMA criteria were followed. No restrictions on heterogeneity level have been considered for meta-analysis. A test for the summary effect measure and heterogeneity ( $\mathrm{I}^{2}$ metric) was used.

Results Seventy-nine papers were selected from 3076 studies (61\% RCTs, 39\% observational studies). Olanzapine and risperidone reported the greatest weight gain and olanzapine the largest BMI increase. Paliperidone showed the highest increase in total cholesterol, but is the only drug reporting an increase in the HDL cholesterol. Quetiapine XR showed the highest decrease in fasting glucose. Lurasidone showed the lowest increase in body weight and a reduction in BMI and was also the only treatment reporting a decrease in total cholesterol and triglycerides. The highest increase in systolic and diastolic blood pressure was reported by quetiapine XR.

Conclusions Despite some limitations (differences in the mean dosages per patient and other side effects not included) this paper provides the first complete meta-analysis on SGAs in variations on metabolic risk profile between start of treatment and end of follow-up, with useful results for clinical practice and possibly for future economic evaluation studies.
\end{abstract}

\section{Introduction}

Schizophrenia is a severe long-term mental health condition that involves cognitive, mood symptoms, behavioral and emotional dysfunctions. The symptoms of schizophrenia are usually classified into positive symptoms - any change in behavior or thoughts, such as hallucinations or delusionsand negative symptoms - where people appear to withdraw from the world around them, take no interest in everyday social interactions, and often appear emotionless and flat. Late adolescence and early adulthood are peak periods for the onset of this disease, that is generally characterized by

Carla Rognoni

carla.rognoni@unibocconi.it

1 Centre for Research on Health and Social Care Management (CERGAS), SDA Bocconi School of Management, Bocconi University, Via Roentgen 1, 20136 Milan, Italy repeated relapses as well as a worsening of psychopathology and social functioning.

Approximately $1.1 \%$ of the adult population is affected and the origin seems to derive from both genetic and environmental factors. According to the Diagnostic and Statistical Manual of Mental Disorders, 5th Edition (DSM-5) criteria [1], it is characterized by at least two of the following six symptoms, each present for a significant portion of time during a 1-month period: delusions, hallucinations, disorganized speech (e.g. frequent derailment or inconsistency), grossly organized behavior or catatonic and negative symptoms (e.g. decreased expression of emotions and abulia).

The treatment of schizophrenia includes antipsychotic (or neuroleptic) drugs. The efficacy of neuroleptics has been extensively investigated and the results show, not only a reduction in the risk of relapse, but also a lower risk of hospitalization for the subjects treated. This translates positively into the quality of life of these patients [2]. 


\section{Key Points}

This study investigated the risk-profile of different second-generation antipsychotics (SGAs) for the treatment of schizophrenia through a meta-analysis by assessing variations between the start of treatment and the end of follow-up.

Olanzapine and risperidone reported the greatest weight gain and olanzapine the largest BMI increase. Paliperidone showed the highest increase in total cholesterol, but is the only drug reporting an increase in the HDL cholesterol. Quetiapine XR showed the highest decrease in fasting glucose. Lurasidone showed the lowest increase in body weight and a reduction in BMI and was also the only treatment reporting a decrease in total cholesterol and triglycerides. The highest increase in systolic and diastolic blood pressure was reported by quetiapine XR.

The evidence on the metabolic risk profile of SGAs may support clinicians in the selection of the appropriate treatment for each patient and the development of economic evaluation studies.

Antipsychotic drugs have been available from the mid1950s; the older types are called typical or first-generation antipsychotics (e.g. chlorpromazine, haloperidol). In the 1990s, new antipsychotic drugs, called second-generation or "atypical" antipsychotics (SGAs) were developed. The first of these SGAs was clozapine, which was followed by risperidone, olanzapine, ziprasidone, quetiapine, amisulpride, sertindole, lurasidone, paliperidone, iloperidone, asenapine, aripiprazole and, more recently, brexpiprazole, cariprazine and zotepine (not in the USA). Some of these SGAs (e.g. paliperidone, aripiprazole, olanzapine, and risperidone) are also available in long-acting injectable (LAI) formulations. The main guidelines recommend SGAs as first choice in both the first episode and in exacerbations. The recommendations on the use of SGAs are supported by a lower incidence of adverse events [3] and, as a consequence, by low discontinuation of therapy [4]. However, SGAs can cause weight gain and considerable changes in the metabolism, which can increase the risk of diabetes and increase circulating cholesterol levels.

Since many SGAs are available, understanding how the many substances compare with each other is important. Few studies focused on the comparison of antipsychotics with placebo in terms of response [5] or considered the real-world effectiveness in preventing relapses [6]. These studies showed that patients improved with antipsychotics compared with placebo, and that clozapine and long-acting injectable antipsychotic medications were the treatments with the highest rate of prevention of schizophrenia relapse. A more recent study reported no consistent superiority of any SGA across efficacy outcomes [7] and most of the literature showed that the main differences between the diverse compounds arise from the tolerability profiles [5, 8-12], especially in terms of metabolic side effects [13].

In the literature there are some systematic reviews comparing side effects, including the metabolic profile of specific oral SGAs in the treatment of schizophrenia. Although most of these studies have been performed in RCT (considered as the gold standard for proving causability), meta-analyses, including observational studies, have been performed as well. The meta-analyses including randomized clinical trials compared the different antipsychotics with placebo $[14,15]$ or different antipsychotics head-to-head $[7,16]$ or performed both comparisons [17]. Effect sizes were in general reported as risk ratios for dichotomous outcomes (e.g. sedation) and as standardized mean differences or mean differences for continuous outcomes (e.g. weight gain). Meta-analyses on observational studies carried out comparisons between the various SGA treatments or with placebo in terms of risk of weight gain or risk of developing type 2 diabetes mellitus $[18,19]$.

The aim of the present paper was to investigate the metabolic and cardiovascular risk profile of the main oral SGAs used in the treatment of adult patients with schizophrenia on the grounds of a systematic review and meta-analysis. In light of the great importance given to the collection and analysis of real-world data for the evaluation of outcomes of new health technologies [20], randomized controlled trials and observational studies have both been considered. Contrary to other published reviews, we assessed the mean variation of the main metabolic parameters between the start of treatment and the end of follow-up for each SGA, reporting detailed results for the different follow-up horizons.

\section{Methods}

The systematic review of the literature was conducted in November 2020 based on the PRISMA criteria (Preferred Reporting Items for Systematic Reviews and Meta-Analyses) [21], starting from a search of the four fundamental elements (population, intervention, comparator, outcomes).

From preliminary research, no studies were found that considered a population to be only European, consequently, no restrictions were imposed on the choice of the base-case population for the analyses.

The drugs taken into consideration were lurasidone, aripiprazole, olanzapine, paliperidone extended release (XR), quetiapine $\mathrm{XR}$ and risperidone, which are the products with the highest market share in the major European countries for 
the treatment of patients with schizophrenia (IQVIA—data on file [22]). The choice also included lurasidone (recently launched onto the market) as a stabilization drug.

Given that no reliable advantage of any SGA emerged across efficacy outcomes [7], the systematic review of the literature has been focused on metabolic and cardiovascular adverse events. In particular, for each drug, variations from final and baseline values have been retrieved for the following parameters (metabolic profile): body weight, body mass index (BMI), total and high-density lipoprotein (HDL) cholesterol, triglycerides, fasting glucose, systolic and diastolic blood pressure.

The scientific databases used for the systematic review of the literature were Pubmed and Web of Science. Studies were considered if published in English and related to an adult population (aged $\geq 18$ years). The research period has been restricted to the last 10 years. No restrictions were applied to the type of study.

The literature search has been performed according to the following:

"schizophrenia" AND ("lurasidone" OR "quetiapine $X R$ " OR "quetiapine extended release" OR "extended release quetiapine" OR "risperidone" $O R$ "olanzapine" $O R$ "aripiprazole" OR "paliperidone") AND ("fasting glucose" OR "fasting plasma glucose" OR "FPG" OR "weight" OR "BMI" OR "HDL" OR "total cholesterol" OR "triglyceride*" OR "blood pressure" OR "hypertension" OR "cardiovascular risk" OR “diabetes").

Abstract and full-text selection was conducted independently by two expert reviewers $(\mathrm{CR}, \mathrm{AB})$. Data were extracted using a customized template developed in Microsoft Excel based on the PICOS statement. Information recorded included study features, participants and treatments characteristics and metabolic profiles.

Data referring to the different treatments were retrieved from all comparative and non-comparative studies identified. Outcomes variations from the different studies, calculated as the difference between the value at the last follow-up and the baseline value, were pooled through a random effect metaanalysis (mean differences) [23] considering the available follow-up. The analyses were performed using Stata ${ }^{\circledR}$ software (StataCorp, version 14) through the "metan" command, which requires two input parameters, effect estimate and standard error. In case the standard deviation was reported for the effect estimate, it was transformed into standard error according to formulas presented in Burns et al. [24].

A test on the summary effect measure is given, as well as a test for heterogeneity, quantified using the $\mathrm{I}^{2}$ metric [25]: the higher the values (from $0 \%$ to $100 \%$ ) the larger the heterogeneity across studies. For the meta-analyses, a broader inclusion criterion has been applied so no restrictions on heterogeneity level have been considered. Results are displayed in forest plots according to different ranges of follow-up duration: $\leq 6$ months, $6<$ months $\leq 12,12<$ months $\leq 24$ and $24<$ months $\leq 36$; this will allow further uses of the meta-analysis results in the context of economic evaluations from short to medium time horizons.

An appraisal of the studies included in the analyses has been performed in order to assess their methodological quality and to determine the extent to which the studies addressed the possibility of bias in their design, conduct and analysis. All papers selected for inclusion in the systematic review have been critically evaluated by two appraisers (CR, $\mathrm{AB}$ ) according to the JBI Critical appraisal tools for randomized controlled trials (RCTs) and cohort studies [26].

The level of evidence (LOE) of the studies was assessed according to a classification provided by the Agency for Healthcare Research and Quality (AHRQ) [27], which considers three categories: high (current evidence derived from RCTs without important limitations), moderate (current evidence derived from RCTs with important limitations or very strong evidence from observational studies or case series), low (current evidence from observational studies, case series or just opinions). In our case, RCTs with lack of doubleblinding, failure to adhere to intention-to-treat analysis or methodological flaws (treatment groups dissimilar at the baseline) were considered together with prospective observational trials and pre-post studies as moderate LOE. Retrospective studies and case series were considered low LOE.

Scenario analyses have been performed by considering only RCTs and by removing the low-quality studies according to the LOE to evaluate the robustness of the results.

\section{Results}

Figure 1 shows the search process according to PRISMA flow-chart. Starting with 3076 identified papers, the analysis focused on 79 that contained useful data for performing the meta-analyses. These were prospective studies $(34 \%$, $n=27)$, retrospective studies $(5 \%, n=4)$ and RCTs $(61 \%$, $n=48$ ), with a total of 37,467 participants (median 69 participants/arm, range 7-5204). The mean age of the population was $36 \pm 7.3$ years and $62 \%$ were male. The number of studies with each individual SGA were: 49 olanzapine, 27 risperidone, 20 aripiprazole, 19 lurasidone, 13 quetiapine and 6 paliperidone.

Table 1 presents the characteristics of the studies included in the quantitative synthesis, which presents only study arms whose drugs are considered in the present study, regardless of whether they were compared with other treatments or placebo, while Table 2 presents the metabolic parameters extracted. Parameter variations for total and HDL cholesterol, triglycerides and fasting glucose were expressed in $\mathrm{mg} / \mathrm{dL}$. To convert millimoles per liter to milligrams per deciliter, we multiplied total and HDL cholesterol values 
by 38.6 , triglycerides values by 88.6 and fasting glucose values by 18 .

Supplementary Table 1 reports metabolic parameters derived by the considered studies while the Supplementary material shows a detailed analysis of results according to the forests plots for the different treatments, follow-up periods and parameters considered. A summary of the main findings considering the complete follow-up horizon of studies is presented in Table 2. The appraisal of the studies according to the risk of bias and LOE is reported in Supplementary Table 2.

From the meta-analyses, lurasidone was shown to be the treatment with a lower increase in body weight $(0.43 \mathrm{~kg})$ and with a decrease in BMI $\left(-0.10 \mathrm{~kg} / \mathrm{m}^{2}\right)$; it was also the only treatment reporting a decrease in total cholesterol $(-8.01 \mathrm{mg} / \mathrm{dL})$ and triglycerides $(-5.33 \mathrm{mg} / \mathrm{dL})$ and the highest decrease in HDL cholesterol $(-2.05 \mathrm{mg} / \mathrm{dL})$.

Olanzapine and risperidone reported the largest weight gain of 4.52 and $4.19 \mathrm{~kg}$, respectively, with significant differences compared with the other treatments. Olanzapine also reported the greatest variation in BMI $\left(1.59 \mathrm{~kg} / \mathrm{m}^{2}\right)$ compared with the other SGAs and significant effects on the variation of triglycerides $(33.10 \mathrm{mg} / \mathrm{dL})$ and fasting glucose $(6.24 \mathrm{mg} / \mathrm{dL})$. Paliperidone showed the highest increase in total cholesterol $(14.69 \mathrm{mg} / \mathrm{dL})$ but reported a positive increase in the HDL cholesterol $(0.57 \mathrm{mg} / \mathrm{dL})$. Aripiprazole was another treatment showing a large increase in triglycerides $(18.63 \mathrm{mg} / \mathrm{dL})$.

The assessment of the variations in diastolic blood pressure was not possible for paliperidone due to lack of data. The highest increase in systolic and diastolic blood pressure was reported by quetiapine XR-2.60 and $2.77 \mathrm{~mm} \mathrm{Hg}$, respectively. Quetiapine XR was also the only drug reporting a decrease in fasting glucose $(-0.59 \mathrm{mg} / \mathrm{dL})$.

The parameters reporting the higher heterogeneity $\left(I^{2}>50 \%\right)$ were body weight (aripiprazole, olanzapine, risperidone), BMI (aripiprazole, olanzapine), HDL cholesterol (olanzapine, risperidone), total cholesterol (olanzapine, risperidone), triglycerides (olanzapine, paliperidone, risperidone), fasting glucose (aripiprazole, olanzapine, risperidone), systolic blood pressure (olanzapine) and diastolic blood pressure (olanzapine, risperidone).

The scenario analysis performed considering only data from RCTs (see Supplementary Table 3) confirmed in
Fig. 1 Preferred reporting items for systematic reviews and meta-analyses (PRISMA) flow chart

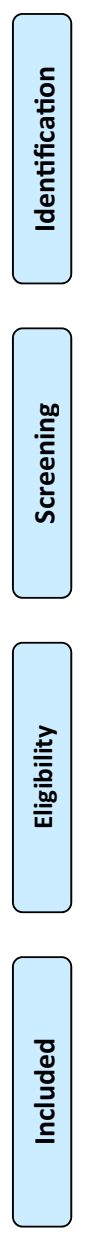

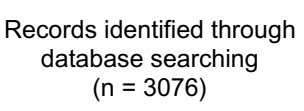

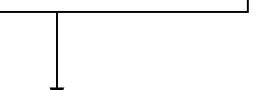
$(n=2353)$

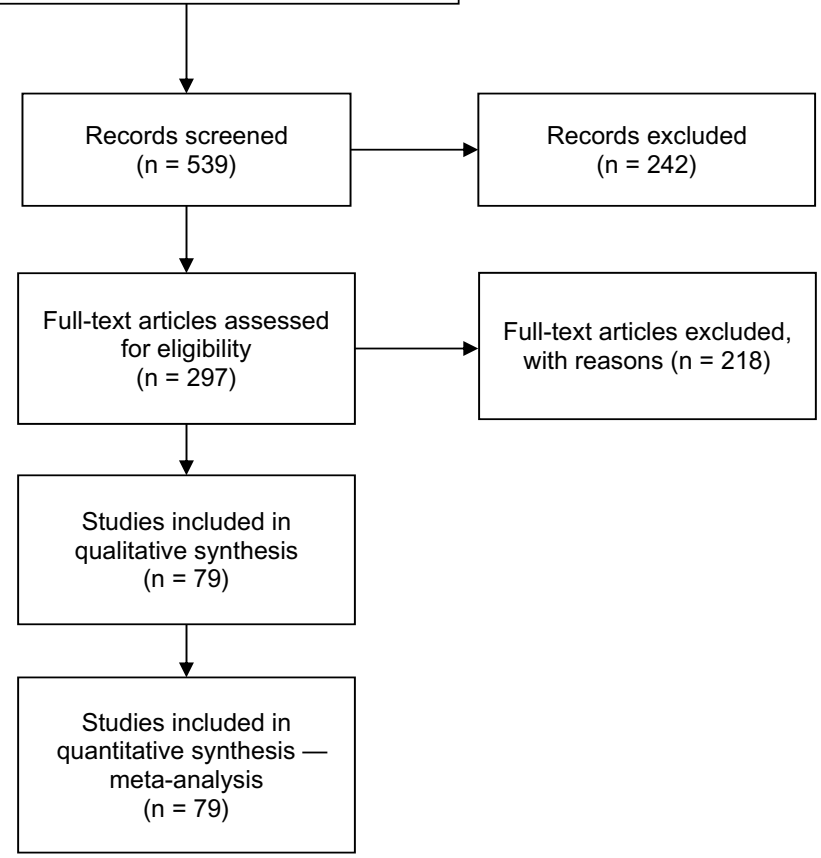




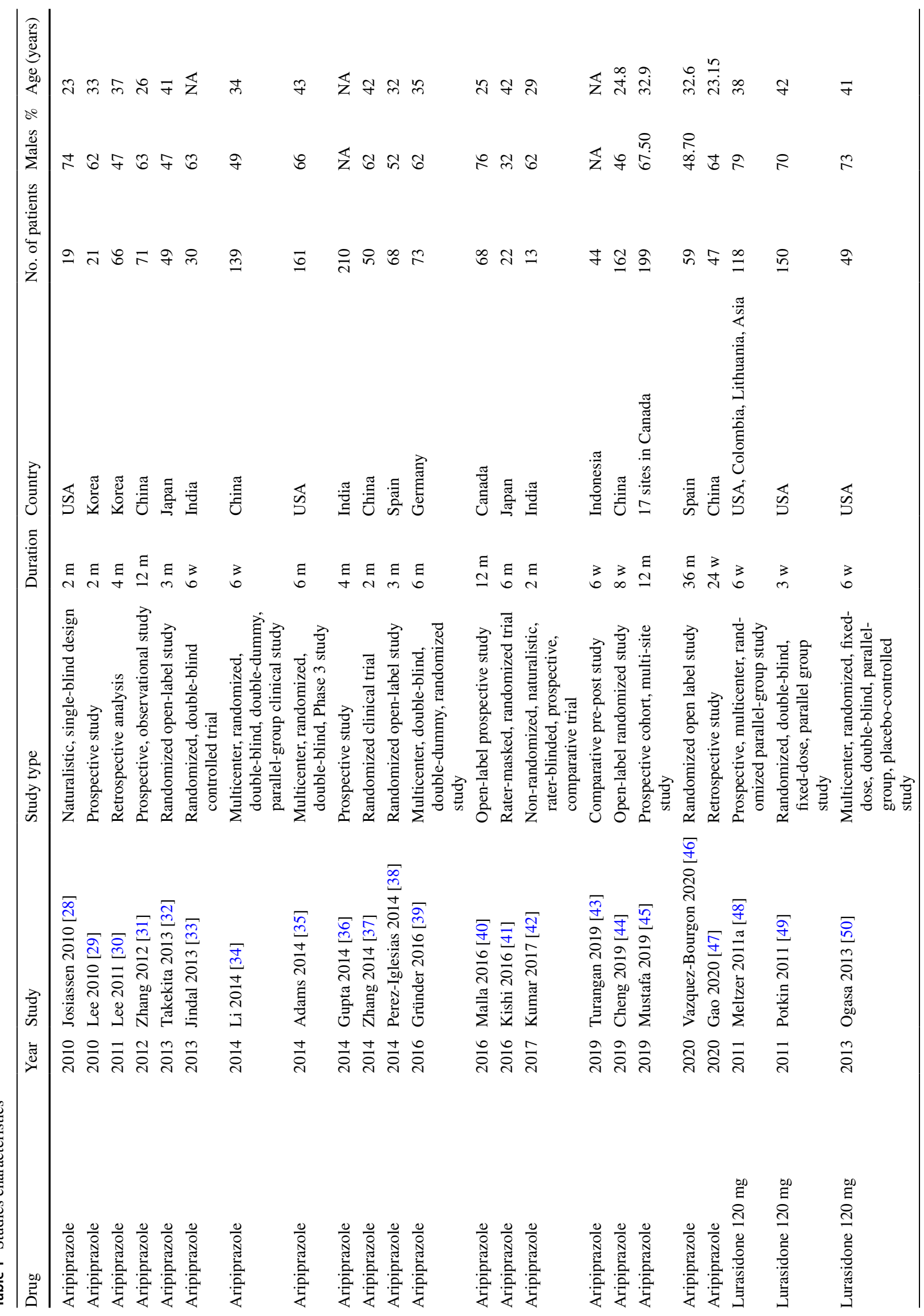




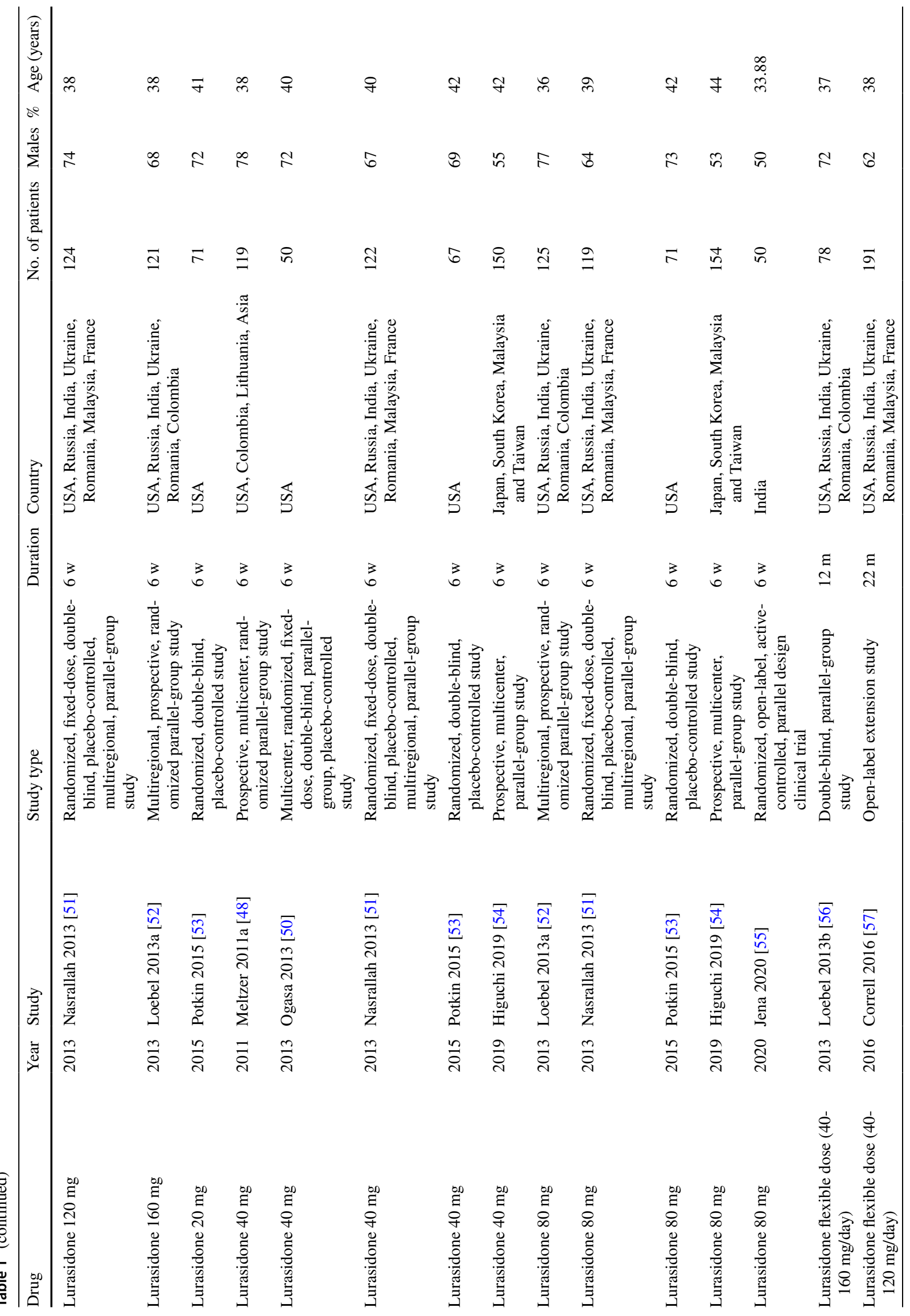




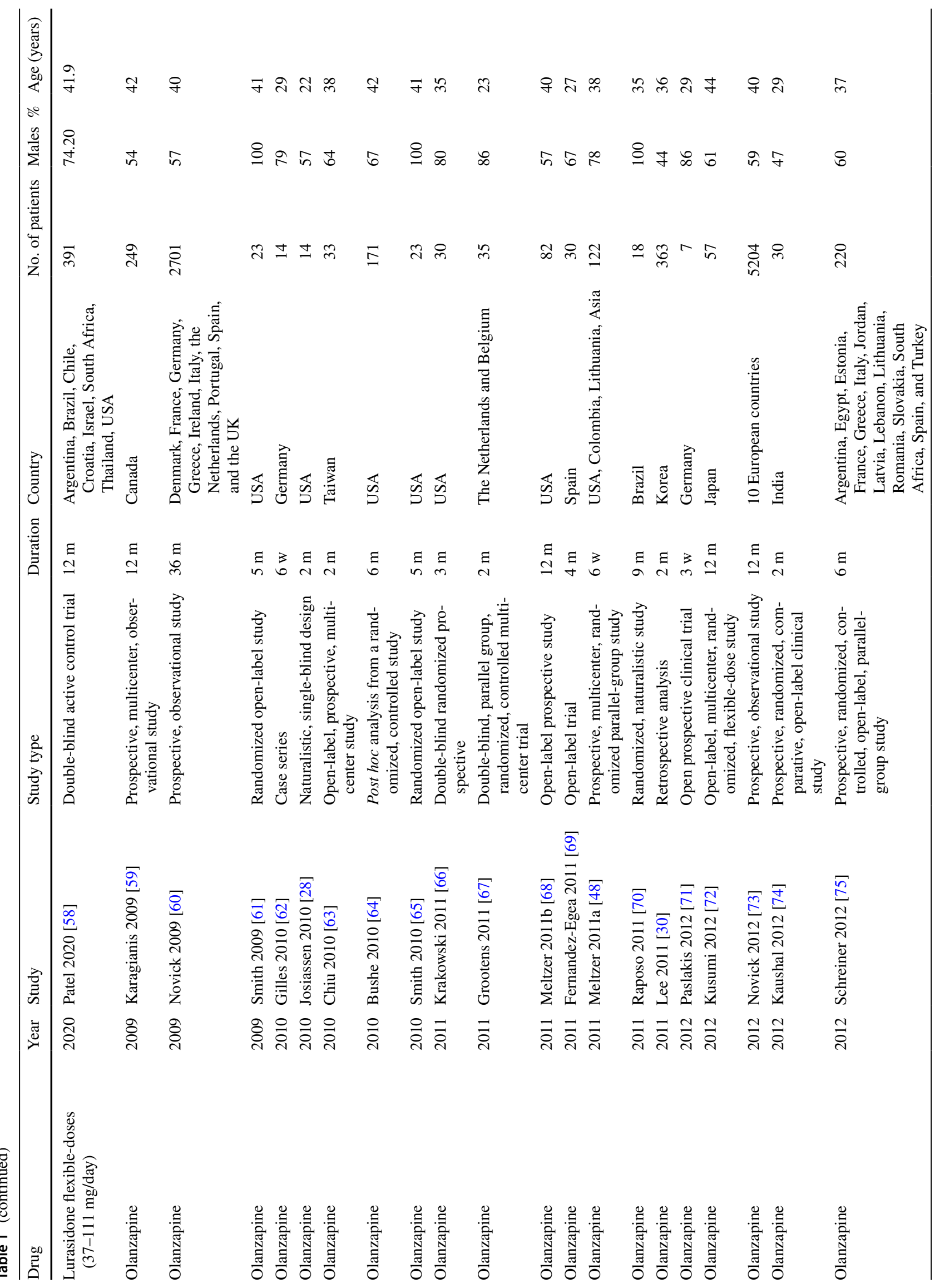




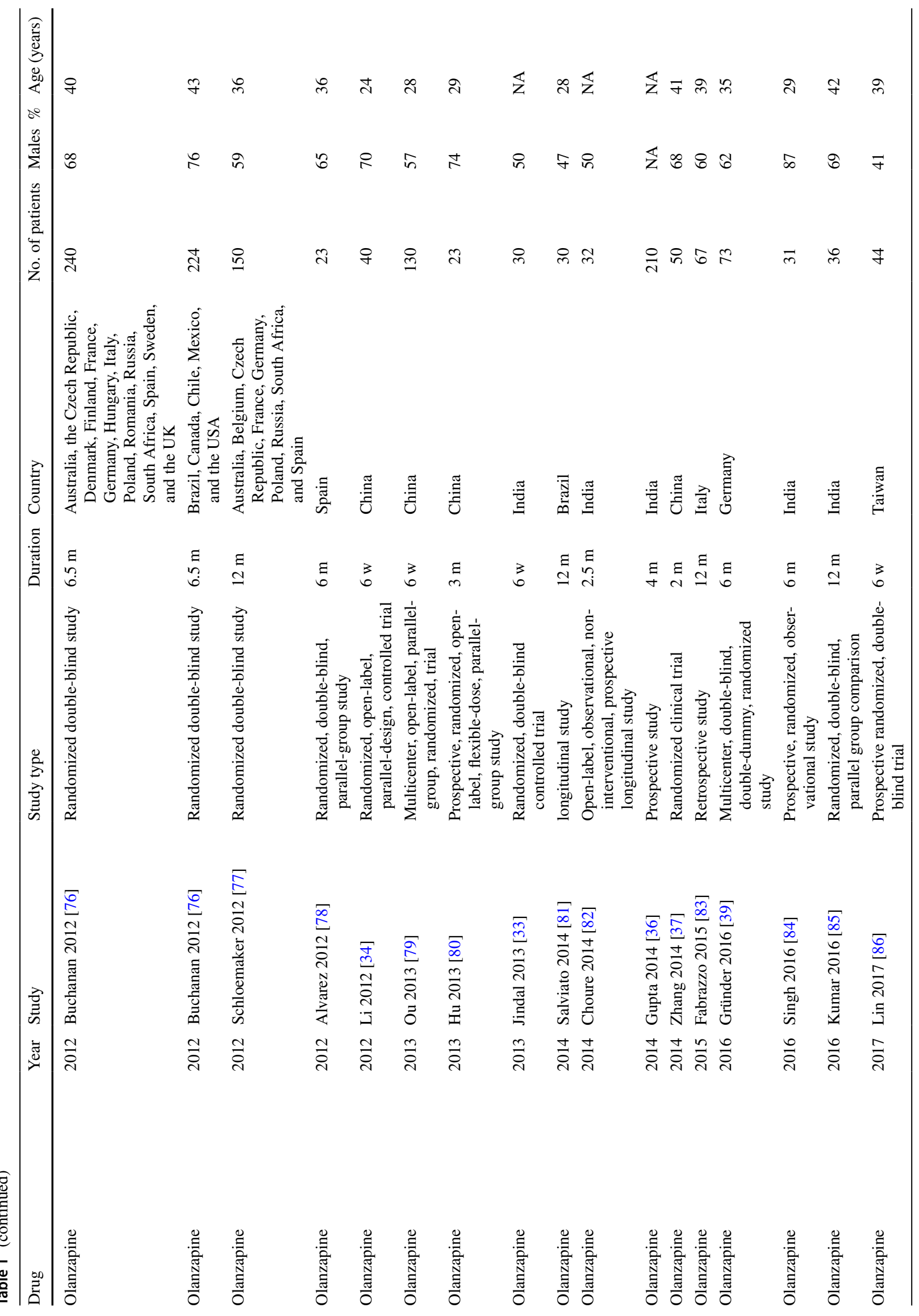




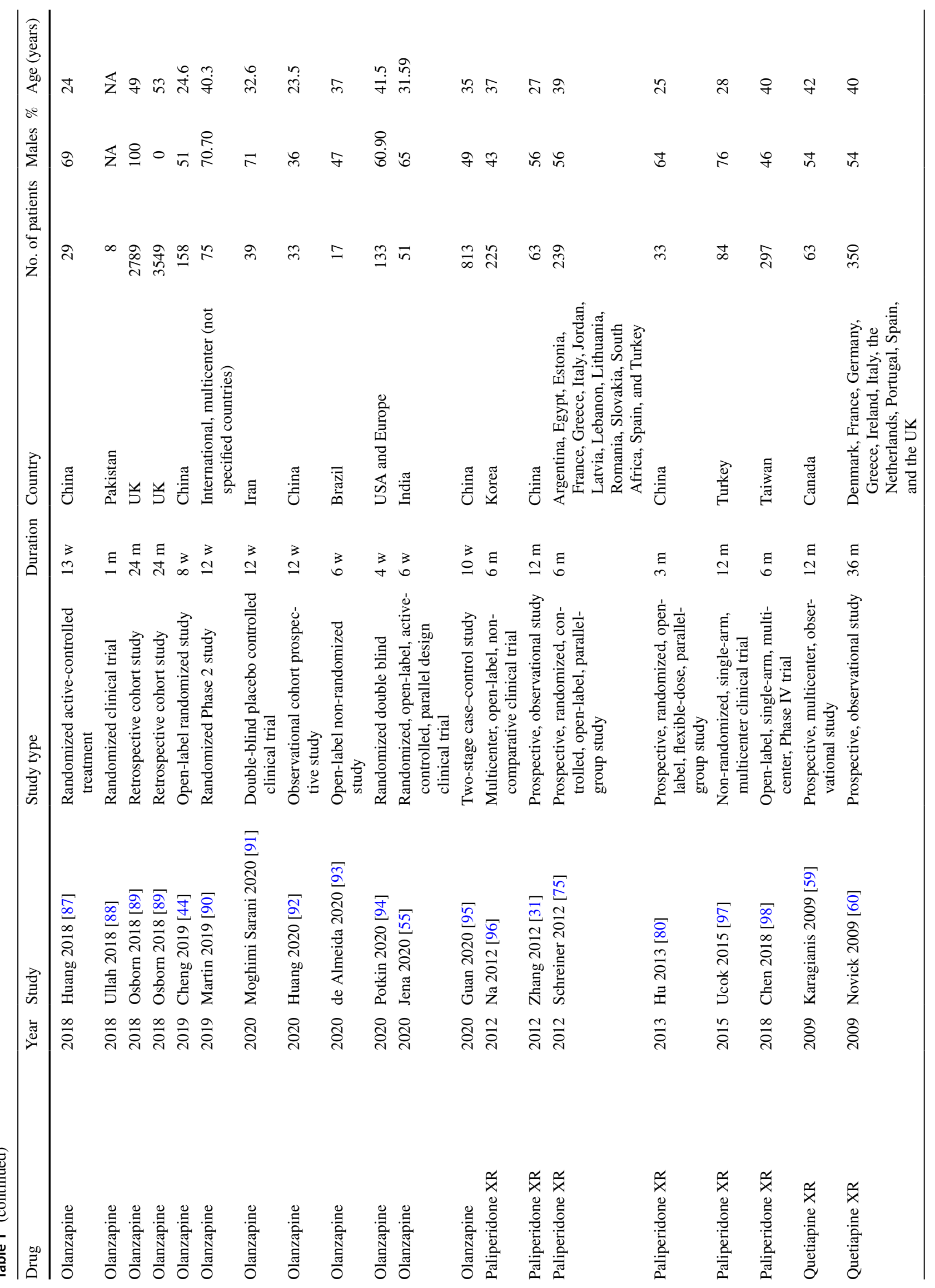




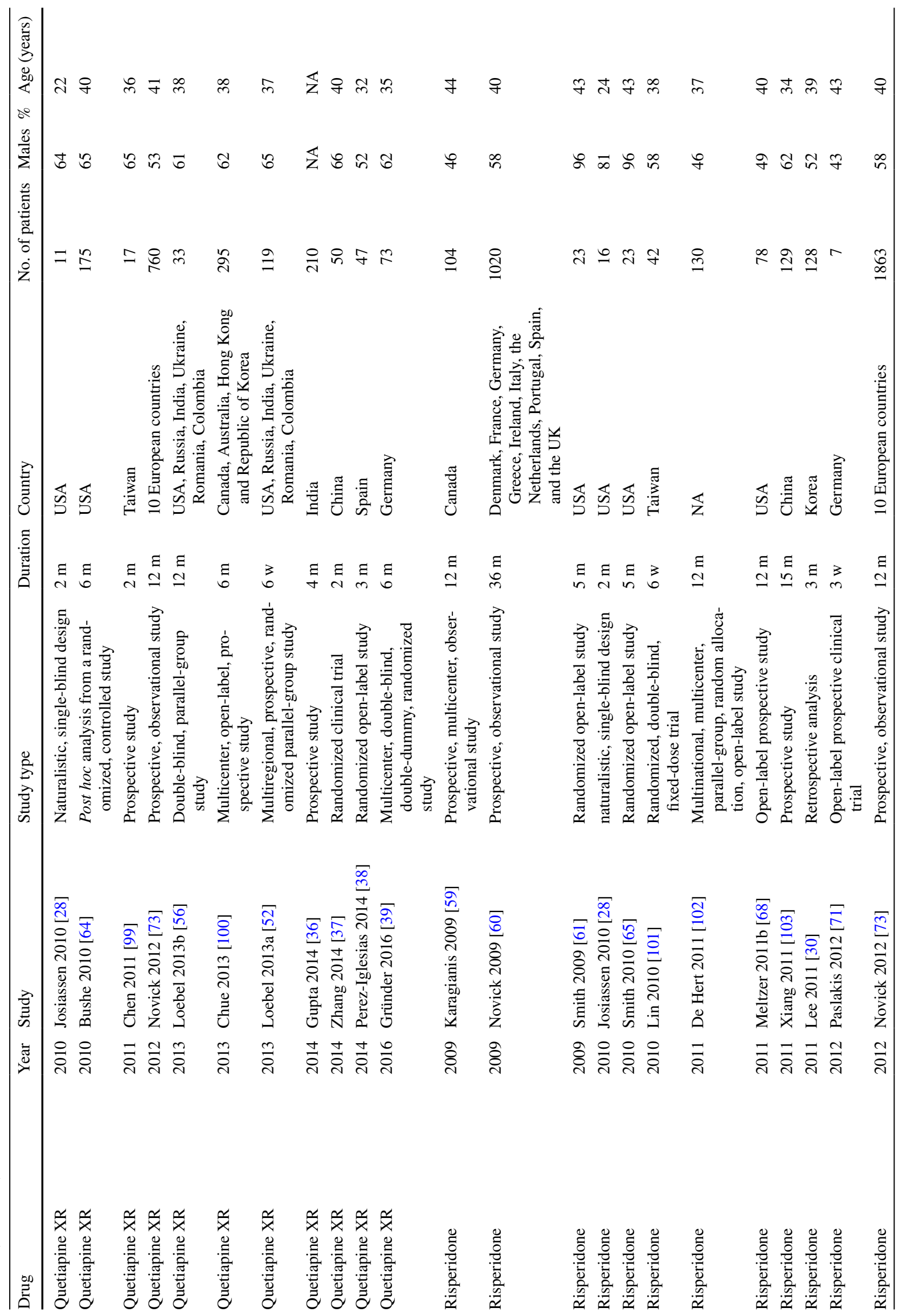




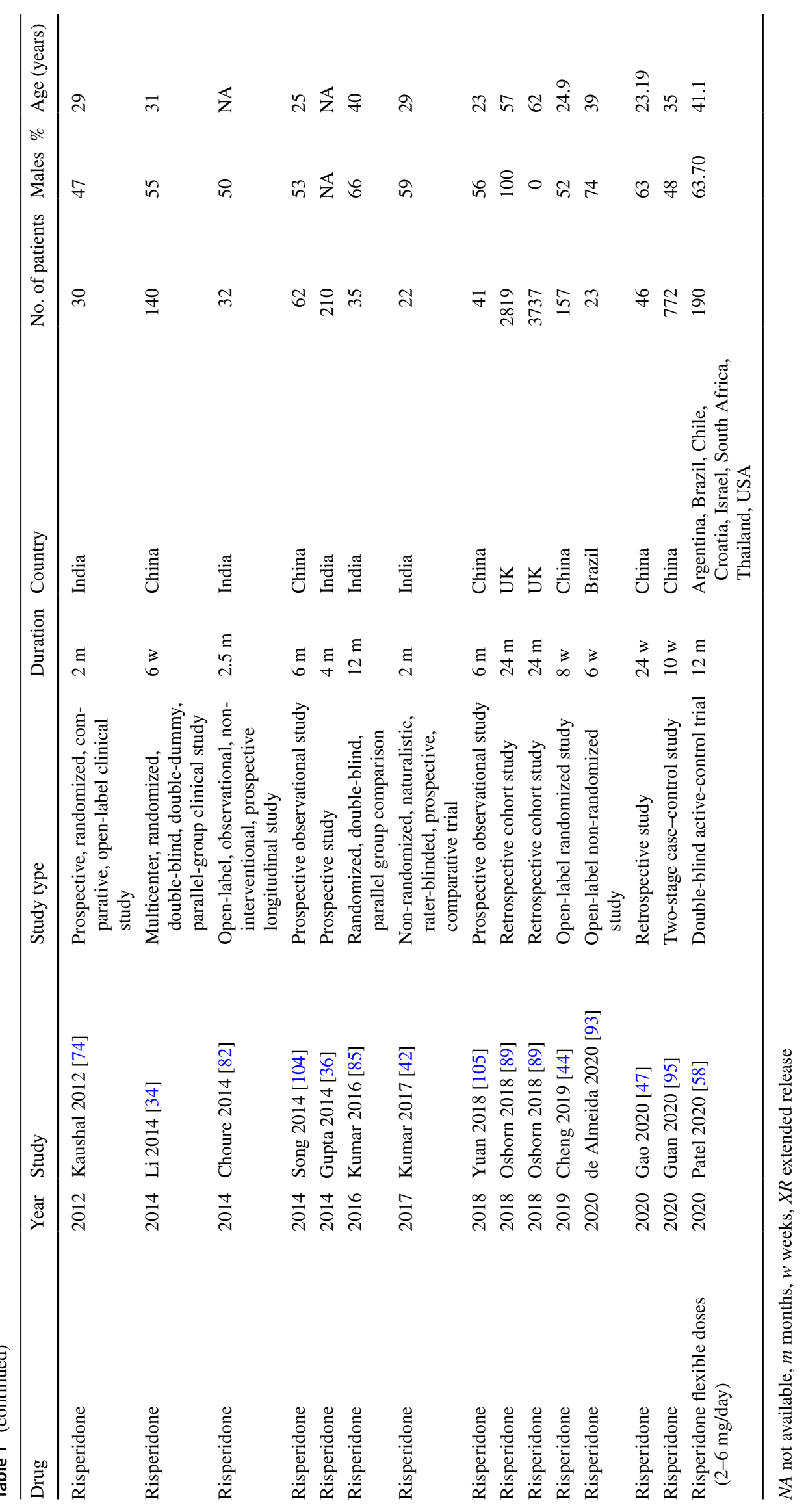


general the results of the base-case analysis, with the exception of aripiprazole, which showed an increase in cholesterol HDL (0.59 vs $-0.62 \mathrm{mg} / \mathrm{dL})$ and risperidone, which reported a decrease in triglycerides (- $3.69 \mathrm{vs} 9.39 \mathrm{mg} / \mathrm{dL})$ and in systolic blood pressure (-2.33 vs $1.07 \mathrm{~mm} \mathrm{Hg}$ ). The scenario analysis conducted excluding low-quality studies (see Supplementary Table 4) showed only small variations in a limited set of parameters compared with the base case.

\section{Discussion and Conclusion}

Schizophrenia is a serious mental illness that affects how a person thinks, feels, and behaves. If left untreated, the symptoms of schizophrenia can be persistent and disabling. Despite its low prevalence (about 1\% of the population) it has great health, social and economic burdens not only for patients but also for families, caregivers, and society. Comorbidities related to metabolic disorders and cardiovascular diseases, such as diabetes, hypertension, metabolic syndrome, and obesity are excessively prevalent among patients with schizophrenia. Compared with the general population, schizophrenia patients have nearly twice the risk of diabetes and metabolic syndrome [106] and an increased risk of mortality for cardiovascular disease, with patients' life expectancy reduced by about 15 years [107]. Although some modifiable cardiovascular disease risk factors, such as sedentary lifestyle, may be associated with schizophrenia, several antipsychotics have been associated with an increased risk of weight gain and other metabolic abnormalities.

The literature reports some meta-analyses [7, 14-19] based on RCTs or observational studies which compared antipsychotics with each other and possibly with placebo in terms of relative risks or differences for the considered parameters. In contrast to these studies, the present work considered both RCTs and observational studies in order to provide results that may be also be extended to clinical practice contexts. Moreover, for each SGA we assessed the mean variation of the metabolic parameters between the start of treatment and the end of follow-up, thus providing immediate and clinically tangible results.

The analyses showed that metabolic effects are not statistically different across medicines although presenting great variations. For weight and BMI gain, respectively, olanzapine and risperidone and olanzapine alone reported significant differences compared with the other SGAs. In particular, olanzapine and risperidone reported a weight gain of 4.52 and $4.19 \mathrm{~kg}$, respectively, while olanzapine reported an increase in BMI of $1.59 \mathrm{~kg} / \mathrm{m}^{2}$. From the meta-analyses, lurasidone was shown to be the treatment with the lowest increase in body weight $(0.43 \mathrm{~kg})$ and with a decrease in BMI $\left(-0.10 \mathrm{~kg} / \mathrm{m}^{2}\right)$. These results are in line with a recent published study that provided a systematic review and 
meta-analysis of randomized trials lasting at least 6 months comparing SGAs head-to-head in schizophrenia and related disorders [7]. The paper reported that weight gain was greater with olanzapine than with all other non-clozapine SGAs and risperidone was significantly worse than several other SGAs. Olanzapine and clozapine have also been reported as the drugs causing greater weight gain compared with most other agents in another recent narrative review [108]. Huhn and colleagues [15] showed that placebo was preferred to olanzapine and risperidone when considering weight increase (mean difference, olanzapine: $2.78 \mathrm{~kg}, 95 \%$ CI 2.44-3.13; risperidone $1.44 \mathrm{~kg}, 95 \%$ CI $1.05-1.83$ ).

The results on total cholesterol and fasting glucose are in line with those reported by Rummel-Kluge and colleagues [16] who showed that olanzapine produced a greater cholesterol increase than aripiprazole and risperidone, while cholesterol increase with quetiapine was greater than with risperidone. From our meta-analyses lurasidone showed a decrease in total cholesterol $(-8.01 \mathrm{mg} / \mathrm{dL})$ and triglycerides $(-5.33 \mathrm{mg} / \mathrm{dL})$ and a moderate variation in fasting glucose $(1.78 \mathrm{mg} / \mathrm{dL})$. Concerning fasting glucose, olanzapine produced the highest increase compared with the other drugs. Our data are in accordance with those derived from the meta-analysis of RCTs and observational studies [14, $18,19,109]$.

The present study has some limitations. First, changes in patients' metabolic profiles have been derived from studies that reported, for each drug, different mean dosages per patient, highlighting that the dose is personalized according to patients' characteristics. Second, the study focused on the analysis of metabolic side effects, without considering the impact of different side effects on patients' quality of life. However, this was out of the scope of the analysis and, furthermore, there are difficulties in assessing the quality of life of patients with schizophrenia because of their cognitive impairments and lack of insight into their disease [110]. Third, the study focused on the analysis of metabolic effects due to the different treatments and did not consider the management of other adverse events.

Despite these limitations, this paper provides evidence on differences in the metabolic effects of SGAs, in a context where recent indications showed no consistent differences in their relative effectiveness.

These findings have important implications not only for clinical practice but also for health economics studies. On the one hand, because currently available antipsychotics vary more with regard to adverse effects than with efficacy, the selection of the appropriate treatment should do no harm to the patient, being mindful that untreated disease can commonly have greater adverse effects than medications. On the other hand, this analysis summarized the evidence on the metabolic impact of SGAs that could be the benchmarks for drugs launched into the market for the same indication, thus integrating the treatment cost with the cost for the management of the metabolic effects. Our findings could be used to perform cost-effectiveness or cost-utility analyses comparing new options with existing treatments and the budget impact of new treatments. A budget impact analysis could also be carried out to estimate the economic impact of a change of prescription mix for current treatment options.

Supplementary Information The online version contains supplementary material available at https://doi.org/10.1007/s40261-021-01000-1.

Acknowledgements The authors would like to thank Aldo Pietro Maggioni (Director of Research Center of Italian Association of Hospital Cardiologists, ANMCO) for having validated the search strategy.

\section{Declarations}

Funding Open access funding provided by Università Commerciale Luigi Bocconi within the CRUI-CAREAgreement.

Conflict of interest The authors do not declare any conflict of interest.

Ethics approval Not applicable.

Consent Not applicable.

Data and/or code availability Data and materials will be available from the authors upon reasonable request.

Authors' contribution CJ: Conceptualization; $\mathrm{CR}, \mathrm{AB}$ : Data curation; CR: Formal analysis; CJ: Funding acquisition; CR, AB: Investigation; CR: Methodology; CJ: Project administration; CJ: Supervision; CJ, $\mathrm{CR}, \mathrm{AB}$ : Writing - review \& editing.

Open Access This article is licensed under a Creative Commons Attribution-NonCommercial 4.0 International License, which permits any non-commercial use, sharing, adaptation, distribution and reproduction in any medium or format, as long as you give appropriate credit to the original author(s) and the source, provide a link to the Creative Commons licence, and indicate if changes were made. The images or other third party material in this article are included in the article's Creative Commons licence, unless indicated otherwise in a credit line to the material. If material is not included in the article's Creative Commons licence and your intended use is not permitted by statutory regulation or exceeds the permitted use, you will need to obtain permission directly from the copyright holder. To view a copy of this licence, visit http://creativecommons.org/licenses/by-nc/4.0/.

\section{References}

1. DSM-5 [Internet]. [cited 2020 Apr 25]. https://www.psychiatry. org/psychiatrists/practice/dsm. Accessed 1 Jan 2021.

2. Matei VP, Mihailescu A, Paraschiv G, Al-Bataineh R, Purnichi T. Weight gain and antipsychotics. Data from eufest study. Acta Endocrinol Buchar Rom 2005. 2016;12:177-84.

3. Mauri MC, Paletta S, Maffini M, Colasanti A, Dragogna F, Di Pace C, et al. Clinical pharmacology of atypical antipsychotics: an update. EXCLI J. 2014;13:1163-91. 
4. Jones PB, Barnes TRE, Davies L, Dunn G, Lloyd H, Hayhurst $\mathrm{KP}$, et al. Randomized controlled trial of the effect on Quality of Life of second- vs first-generation antipsychotic drugs in schizophrenia: Cost Utility of the Latest Antipsychotic Drugs in Schizophrenia Study (CUtLASS 1). Arch Gen Psychiatry. 2006;63:1079-87.

5. Leucht S, Leucht C, Huhn M, Chaimani A, Mavridis D, Helfer B, et al. Sixty years of placebo-controlled antipsychotic drug trials in acute schizophrenia: systematic review, bayesian metaanalysis, and meta-regression of efficacy predictors. Am J Psychiatry. 2017;174:927-42.

6. Tiihonen J, Mittendorfer-Rutz E, Majak M, Mehtälä J, Hoti F, Jedenius E, et al. Real-world effectiveness of antipsychotic treatments in a nationwide cohort of 29823 patients with schizophrenia. JAMA Psychiatry. 2017;74:686-93.

7. Kishimoto T, Hagi K, Nitta M, Kane JM, Correll CU. Longterm effectiveness of oral second-generation antipsychotics in patients with schizophrenia and related disorders: a systematic review and meta-analysis of direct head-to-head comparisons. World Psychiatry Off J World Psychiatr Assoc WPA. 2019;18:208-24.

8. Komossa K, Rummel-Kluge C, Schmid F, Hunger H, Schwarz S, El-Sayeh HGG, et al. Aripiprazole versus other atypical antipsychotics for schizophrenia. Cochrane Database Syst Rev. 2009;CD006569.

9. Komossa K, Rummel-Kluge C, Hunger H, Schwarz S, Bhoopathi PSS, Kissling W, et al. Ziprasidone versus other atypical antipsychotics for schizophrenia. Cochrane Database Syst Rev. 2009;CD006627.

10. Cipriani A, Boso M, Barbui C. Clozapine combined with different antipsychotic drugs for treatment resistant schizophrenia. Cochrane Database Syst Rev. 2009;CD006324.

11. Komossa K, Rummel-Kluge C, Hunger H, Schmid F, Schwarz S, Silveira da Mota Neto JI, et al. Amisulpride versus other atypical antipsychotics for schizophrenia. Cochrane Database Syst Rev. 2010;CD006624.

12. Wang J, Omori IM, Fenton M, Soares B. Sulpiride augmentation for schizophrenia. Schizophr Bull. 2010;36:229-30.

13. Haupt DW. Differential metabolic effects of antipsychotic treatments. Eur Neuropsychopharmacol. 2006;16:S149-55.

14. Pillinger T, McCutcheon RA, Vano L, Mizuno Y, Arumuham A, Hindley G, et al. Comparative effects of 18 antipsychotics on metabolic function in patients with schizophrenia, predictors of metabolic dysregulation, and association with psychopathology: a systematic review and network meta-analysis. Lancet Psychiatry. 2020;7:64-77.

15. Huhn M, Nikolakopoulou A, Schneider-Thoma J, Krause M, Samara M, Peter N, et al. Comparative efficacy and tolerability of 32 oral antipsychotics for the acute treatment of adults with multi-episode schizophrenia: a systematic review and network meta-analysis. Lancet Lond Engl. 2019;394:939-51.

16. Rummel-Kluge C, Komossa K, Schwarz S, Hunger H, Schmid F, Lobos CA, et al. Head-to-head comparisons of metabolic side effects of second-generation antipsychotics in the treatment of schizophrenia: a systematic review and meta-analysis. Schizophr Res. 2010;123:225-33.

17. Zhang Y, Liu Y, Su Y, You Y, Ma Y, Yang G, et al. The metabolic side effects of 12 antipsychotic drugs used for the treatment of schizophrenia on glucose: a network meta-analysis. BMC Psychiatry. 2017;17:373.

18. Hirsch L, Yang J, Bresee L, Jette N, Patten S, Pringsheim T. Second-generation antipsychotics and metabolic side effects: a systematic review of population-based studies. Drug Saf. 2017;40:771-81.

19. Stubbs B, Vancampfort D, De Hert M, Mitchell AJ. The prevalence and predictors of type two diabetes mellitus in people with schizophrenia: a systematic review and comparative metaanalysis. Acta Psychiatr Scand. 2015;132:144-57.

20. Berger ML, Sox H, Willke RJ, Brixner DL, Eichler H-G, Goettsch W, et al. Good practices for real-world data studies of treatment and/or comparative effectiveness: recommendations from the joint ISPOR-ISPE Special Task Force on real-world evidence in health care decision making. Pharmacoepidemiol Drug Saf. 2017;26:1033-9.

21. Moher D, Liberati A, Tetzlaff J, Altman DG; PRISMA Group. Preferred reporting items for systematic reviews and metaanalyses: the PRISMA statement. BMJ. 2009;21:339:b2535. https://doi.org/10.1136/bmj.b2535.

22. IQVIA Home Solutions sticky hovers. http://view.ceros.com/ quintiles-ims/iqvia-home-solutions-2-1. Accessed 1 Jan 2021.

23. Chapter 9: Summarizing study characteristics and preparing for synthesis. https://training.cochrane.org/handbook/current/ chapter-09. Accessed 1 Jan 2021.

24. Burns R.B., Dobson C.B. (1981) Standard error of the difference between means. In: Experimental Psychology. Springer, Dordrecht. https://doi.org/10.1007/978-94-011-7241-7_15.

25. Higgins JPT, Thompson SG, Deeks JJ, Altman DG. Measuring inconsistency in meta-analyses. BMJ. 2003;327:557-60.

26. Aromataris E, Munn Z (Editors). JBI Manual for Evidence Synthesis. JBI, 2020. Available from https://synthesismanual. jbi.global. Accessed 1 Jan 2021.

27. Guidelines and Measuresl Agency for Healthcare Research and Quality. https://www.ahrq.gov/gam/index.html. Accessed 1 Jan 2021.

28. Josiassen RC, Shaughnessy RA, Filymer DM, Donohue AM, Kacso M, Finkel N, et al. Early intervention with second-generation antipsychotics in first-episode psychosis: results of an 8-week naturalistic study. Early Interv Psychiatry. 2010;4:57-63.

29. Lee H-Y, Ham B-J, Kang R-H, Paik J-W, Hahn S-W, Lee M-S, et al. Trial of aripiprazole in the treatment of first-episode schizophrenia. Psychiatry Clin Neurosci. 2010;64:38-43.

30. Lee S-Y, Park M-H, Patkar AA, Pae C-U. A retrospective comparison of BMI changes and the potential risk factors among schizophrenic inpatients treated with aripiprazole, olanzapine, quetiapine or risperidone. Prog Neuropsychopharmacol Biol Psychiatry. 2011;35:490-6.

31. Zhang Y, Dai G. Efficacy and metabolic influence of paliperidone $\mathrm{ER}$, aripiprazole and ziprasidone to patients with first-episode schizophrenia through 52 weeks follow-up in China. Hum Psychopharmacol. 2012;27:605-14.

32. Takekita Y, Kato M, Wakeno M, Sakai S, Suwa A, Nishida K, et al. A 12-week randomized, open-label study of perospirone versus aripiprazole in the treatment of Japanese schizophrenia patients. Prog Neuropsychopharmacol Biol Psychiatry. 2013;40:110-4.

33. Jindal KC, Singh GP, Munjal V. Aripiprazole versus olanzapine in the treatment of schizophrenia: a clinical study from India. Int J Psychiatry Clin Pract. 2013;17:21-9.

34. Li H, Luo J, Wang C, Xie S, Xu X, Wang X, et al. Efficacy and safety of aripiprazole in Chinese Han schizophrenia subjects: a randomized, double-blind, active parallel-controlled, multicenter clinical trial. Schizophr Res. 2014;157:112-9.

35. Adams DH, Zhang L, Millen BA, Kinon BJ, Gomez J-C. Pomaglumetad methionil (LY2140023 monohydrate) and aripiprazole in patients with schizophrenia: a phase 3, multicenter, doubleblind comparison. Schizophr Res Treat. 2014;2014:758212.

36. Gupta A, Dadheech G, Yadav D, Sharma P, Gautam S. Metabolic issues in schizophrenic patients receiving antipsychotic treatment. Indian J Clin Biochem. 2014;29:196-201.

37. Zhang S, Lan G. Prospective 8-week trial on the effect of olanzapine, quetiapine, and aripiprazole on blood glucose and lipids 
among individuals with first-onset schizophrenia. Shanghai Arch Psychiatry. 2014;26:339-46.

38. Pérez-Iglesias R, Ortiz-Garcia de la Foz V, Martínez García O, Amado JA, Garcia-Unzueta MT, Ayesa-Arriola R, et al. Comparison of metabolic effects of aripiprazole, quetiapine and ziprasidone after 12 weeks of treatment in first treated episode of psychosis. Schizophr Res. 2014;159:90-4.

39. Gründer G, Heinze M, Cordes J, Mühlbauer B, Juckel G, Schulz C, et al. Effects of first-generation antipsychotics versus second-generation antipsychotics on quality of life in schizophrenia: a double-blind, randomised study. Lancet Psychiatry. 2016;3:717-29.

40. Malla A, Mustafa S, Rho A, Abadi S, Lepage M, Joober R. Therapeutic effectiveness and tolerability of aripiprazole as initial choice of treatment in first episode psychosis in an early intervention service: a one-year outcome study. Schizophr Res. 2016;174:120-5.

41. Kishi T, Matsuda Y, Matsunaga S, Mukai T, Moriwaki M, Tabuse $\mathrm{H}$, et al. A randomized trial of aripiprazole vs blonanserin for the treatment of acute schizophrenia and related disorders. Neuropsychiatr Dis Treat. 2016;12:3041-9.

42. Kumar PBS, Pandey RS, Thirthalli J, Kumar PTS, Kumar CN. A comparative study of short term efficacy of aripiprazole and risperidone in schizophrenia. Curr Neuropharmacol. 2017;15:1073-84.

43. Turangan DR, Loebis B, Husada SM, Nasution NM. Differences of fasting blood glucose level in people with schizophrenia between before and after getting aripiprazole treatment. Open Access Maced J Med Sci. 2019;7:2607-11.

44. Cheng Z, Yuan Y, Han X, Yang L, Cai S, Yang F, et al. An open-label randomised comparison of aripiprazole, olanzapine and risperidone for the acute treatment of first-episode schizophrenia: eight-week outcomes. J Psychopharmacol Oxf Engl. 2019;33:1227-36.

45. Mustafa S, Bougie J, Miguelez M, Clerzius G, Rampakakis E, Proulx J, et al. Real-life assessment of aripiprazole monthly (Abilify Maintena) in schizophrenia: a Canadian naturalistic non-interventional prospective cohort study. BMC Psychiatry. 2019;19:114

46. Vázquez-Bourgon J, Ibáñez Alario M, Mayoral-van Son J, Gómez Revuelta M, Ayesa Arriola R, Juncal Ruiz M, et al. A 3 -year prospective study on the metabolic effect of aripiprazole, quetiapine and ziprasidone: a pragmatic clinical trial in first episode psychosis patients. Eur Neuropsychopharmacol J Eur Coll Neuropsychopharmacol. 2020;39:46-55.

47. Gao L, Zhang X, Jiang Z, Li H. Effects on social functioning and metabolism in the patients with first-episode schizophrenia: aipiprazole vs risperidone. Int J Clin Exp Med. 2020;13(4):2888-94.

48. Meltzer HY, Cucchiaro J, Silva R, Ogasa M, Phillips D, Xu $\mathrm{J}$, et al. Lurasidone in the treatment of schizophrenia: a randomized, double-blind, placebo- and olanzapine-controlled study. Am J Psychiatry. 2011;168:957-67.

49. Potkin SG, Ogasa M, Cucchiaro J, Loebel A. Double-blind comparison of the safety and efficacy of lurasidone and ziprasidone in clinically stable outpatients with schizophrenia or schizoaffective disorder. Schizophr Res. 2011;132:101-7.

50. Ogasa M, Kimura T, Nakamura M, Guarino J. Lurasidone in the treatment of schizophrenia: a 6-week, placebo-controlled study. Psychopharmacology. 2013;225:519-30.

51. Nasrallah HA, Silva R, Phillips D, Cucchiaro J, Hsu J, Xu J, et al. Lurasidone for the treatment of acutely psychotic patients with schizophrenia: a 6-week, randomized, placebo-controlled study. J Psychiatr Res. 2013;47:670-7.

52. Loebel A, Cucchiaro J, Sarma K, Xu L, Hsu C, Kalali AH, et al. Efficacy and safety of lurasidone $80 \mathrm{mg} /$ day and $160 \mathrm{mg} /$ day in the treatment of schizophrenia: a randomized, doubleblind, placebo- and active-controlled trial. Schizophr Res. 2013;145:101-9.

53. Potkin SG, Kimura T, Guarino J. A 6-week, double-blind, placebo- and haloperidol-controlled, phase II study of lurasidone in patients with acute schizophrenia. Ther Adv Psychopharmacol. 2015;5:322-31.

54. Higuchi T, Ishigooka J, Iyo M, Yeh C-B, Ebenezer EG, Liang $\mathrm{KY}$, et al. Lurasidone in the treatment of schizophrenia: results of a double-blind, placebo-controlled trial in Asian patients. Asia-Pac Psychiatry Off J Pac Rim Coll Psychiatr. 2019;11:e12352.

55. Jena M, Mishra A, Mishra BR, Nath S, Maiti R. Effect of lurasidone versus olanzapine on cardiometabolic parameters in unmedicated patients with schizophrenia: a randomized controlled trial. Psychopharmacology. 2020;237:3471-80.

56. Loebel A, Cucchiaro J, Xu J, Sarma K, Pikalov A, Kane JM. Effectiveness of lurasidone vs. quetiapine XR for relapse prevention in schizophrenia: a 12-month, double-blind, noninferiority study. Schizophr Res. 2013;147:95-102.

57. Correll CU, Cucchiaro J, Silva R, Hsu J, Pikalov A, Loebel A. Long-term safety and effectiveness of lurasidone in schizophrenia: a 22-month, open-label extension study. CNS Spectr. 2016;21:393-402.

58. Patel PJ, Weidenfeller C, Jones AP, Nilsson J, Hsu J. LongTerm Assessment of Lurasidone in Schizophrenia: Post Hoc Analysis of a 12-Month, Double Blind, Active-Controlled Trial and 6-Month Open-Label Extension Study. Neurol Ther. 2020. https://doi.org/10.1007/s40120-020-00221-4.

59. Karagianis J, Williams R, Davis L, Procyshyn R, Monga N, Hanley J, et al. Antipsychotic switching: results from a one-year prospective, observational study of patients with schizophrenia. Curr Med Res Opin. 2009;25:2121-32.

60. Novick D, Haro JM, Perrin E, Suarez D, Texeira JM. Tolerability of outpatient antipsychotic treatment: 36-month results from the European Schizophrenia Outpatient Health Outcomes (SOHO) study. Eur Neuropsychopharmacol J Eur Coll Neuropsychopharmacol. 2009;19:542-50.

61. Smith RC, Lindenmayer J-P, Davis JM, Kelly E, Viviano TF, Cornwell J, et al. Effects of olanzapine and risperidone on glucose metabolism and insulin sensitivity in chronic schizophrenic patients with long-term antipsychotic treatment: a randomized 5-month study. J Clin Psychiatry. 2009;70:1501-13.

62. Gilles M, Hentschel F, Paslakis G, Glahn V, Lederbogen F, Deuschle M. Visceral and subcutaneous fat in patients treated with olanzapine: a case series. Clin Neuropharmacol. 2010;33:248-9.

63. Chiu C-C, Chen C-H, Chen B-Y, Yu S-H, Lu M-L. The timedependent change of insulin secretion in schizophrenic patients treated with olanzapine. Prog Neuropsychopharmacol Biol Psychiatry. 2010;34:866-70.

64. Bushe C, Sniadecki J, Bradley AJ, Poole Hoffmann V. Comparison of metabolic and prolactin variables from a six-month randomised trial of olanzapine and quetiapine in schizophrenia. J Psychopharmacol Oxf Engl. 2010;24:1001-9.

65. Smith RC, Lindenmayer J-P, Hu Q, Kelly E, Viviano TF, Cornwell J, et al. Effects of olanzapine and risperidone on lipid metabolism in chronic schizophrenic patients with long-term antipsychotic treatment: a randomized five month study. Schizophr Res. 2010;120:204-9.

66. Krakowski M, Czobor P. Cholesterol and cognition in schizophrenia: a double-blind study of patients randomized to clozapine, olanzapine and haloperidol. Schizophr Res. 2011;130:27-33.

67. Grootens KP, van Veelen NMJ, Peuskens J, Sabbe BGC, Thys $\mathrm{E}$, Buitelaar JK, et al. Ziprasidone vs olanzapine in recent-onset schizophrenia and schizoaffective disorder: results of an 8-week 
double-blind randomized controlled trial. Schizophr Bull. 2011;37:352-61.

68. Meltzer HY, Bonaccorso S, Bobo WV, Chen Y, Jayathilake K. A 12-month randomized, open-label study of the metabolic effects of olanzapine and risperidone in psychotic patients: influence of valproic acid augmentation. J Clin Psychiatry. 2011;72:1602-10.

69. Fernandez-Egea E, Miller B, Garcia-Rizo C, Bernardo M, Kirkpatrick B. Metabolic effects of olanzapine in patients with newly diagnosed psychosis. J Clin Psychopharmacol. 2011;31:154-9.

70. Raposo NRB, Ferreira AS, Gattaz WF. Body mass index increase, serum leptin, adiponectin, neuropeptide $\mathrm{Y}$ and lipid levels during treatment with olanzapine and haloperidol. Pharmacopsychiatry. 2011;44:169-72.

71. Paslakis G, Deuschle M, Thome J, Rüsse S, Kopf D. The differential effect of risperidone and olanzapine on insulin sensitivity after 3 weeks of treatment: a HOMA pilot study. Pharmacopsychiatry. 2012;45:96-9.

72. Kusumi I, Honda M, Uemura K, Sugawara Y, Kohsaka M, Tochigi A, et al. Effect of olanzapine orally disintegrating tablet versus oral standard tablet on body weight in patients with schizophrenia: a randomized open-label trial. Prog Neuropsychopharmacol Biol Psychiatry. 2012;36:313-7.

73. Novick D, Ascher-Svanum H, Haro JM, Bertsch J, Takahashi M. Schizophrenia Outpatient Health Outcomes study: twelve-month findings. Pragmatic Obs Res. 2012;3:27-40.

74. Kaushal J, Bhutani G, Gupta R. Comparison of fasting blood sugar and serum lipid profile changes after treatment with atypical antipsychotics olanzapine and risperidone. Singapore Med J. 2012;53:488-92.

75. Schreiner A, Niehaus D, Shuriquie NA, Aadamsoo K, Korcsog $\mathrm{P}$, Salinas R, et al. Metabolic effects of paliperidone extended release versus oral olanzapine in patients with schizophrenia: a prospective, randomized, controlled trial. J Clin Psychopharmacol. 2012;32:449-57.

76. Buchanan RW, Panagides J, Zhao J, Phiri P, den Hollander W, Ha $\mathrm{X}$, et al. Asenapine versus olanzapine in people with persistent negative symptoms of schizophrenia. J Clin Psychopharmacol. 2012;32:36-45.

77. Schoemaker J, Stet L, Vrijland P, Naber D, Panagides J, Emsley R. Long-term efficacy and safety of asenapine or olanzapine in patients with schizophrenia or schizoaffective disorder: an extension study. Pharmacopsychiatry. 2012;45:196-203.

78. Álvarez E, Bernardo M, Gutiérrez Casares JR, Montejo ÁL. Ziprasidone versus Olanzapine in the weight gain associated with the treatment of schizophrenia: a six-month double-blind randomized parallel group study. Eur J Psychiatry. 2012;26:248-59.

79. Ou J-J, Xu Y, Chen H-H, Fan X, Gao K, Wang J, et al. Comparison of metabolic effects of ziprasidone versus olanzapine treatment in patients with first-episode schizophrenia. Psychopharmacology. 2013;225:627-35.

80. Hu S, Yao M, Peterson BS, Xu D, Hu J, Tang J, et al. A randomized, 12-week study of the effects of extended-release paliperidone (paliperidone ER) and olanzapine on metabolic profile, weight, insulin resistance, and $\beta$-cell function in schizophrenic patients. Psychopharmacology. 2013;230:3-13.

81. Salviato Balbão M, Cecílio Hallak JE, Arcoverde Nunes E, Homem de Mello M, Triffoni-Melo A de T, Ferreira FI de $\mathrm{S}$, et al. Olanzapine, weight change and metabolic effects: a naturalistic 12-month follow up. Ther Adv Psychopharmacol. 2014;4:30-6.

82. Choure BK, Gosavi D, Nanotkar S. Comparative cardiovascular safety of risperidone and olanzapine, based on electrocardiographic parameters and blood pressure: a prospective open label observational study. Indian J Pharmacol. 2014;46:493-7.

83. Fabrazzo M, Monteleone P, Prisco V, Perris F, Catapano F, Tortorella A, et al. Olanzapine is faster than haloperidol in inducing metabolic abnormalities in schizophrenic and bipolar patients. Neuropsychobiology. 2015;72:29-36.

84. Singh S, Chandra S, Kapoor AK, Singh HK, Kant R. Metabolic effects of Olanzapine versus Iloperidone: a 24 weeks randomized, prospective, interventional study. Internet J Med Update EJOURNAL. 2016;11:17-24.

85. Suresh Kumar PN, Anish PK, Rajmohan V. Olanzapine has better efficacy compared to risperidone for treatment of negative symptoms in schizophrenia. Indian J Psychiatry. 2016;58:311-6.

86. Lin C-H, Wang F-C, Lin S-C, Huang Y-H, Chen C-C. A randomized, double-blind, comparison of the efficacy and safety of low-dose olanzapine plus low-dose trifluoperazine versus fulldose olanzapine in the acute treatment of schizophrenia. Schizophr Res. 2017;185:80-7.

87. Huang M, Yu L, Pan F, Lu S, Hu S, Hu J, et al. A randomized, 13-week study assessing the efficacy and metabolic effects of paliperidone palmitate injection and olanzapine in first-episode schizophrenia patients. Prog Neuropsychopharmacol Biol Psychiatry. 2018;81:122-30.

88. Ullah S, Subhan F, Sultan SM, Muhammad A, Rauf K, Ali G, Shah R. Comparative Evaluation of Controlled Release Tablets Versus Reference Tablets of Olanzapine for Therapeutic Efficacy and Clinical Safety in Schizophrenic Patients. Lat. Am. J. Pharm. 2018;37(2):245-53.

89. Osborn DP, Petersen I, Beckley N, Walters K, Nazareth I, Hayes $\mathrm{J}$. Weight change over two years in people prescribed olanzapine, quetiapine and risperidone in UK primary care: cohort study in THIN, a UK primary care database. J Psychopharmacol Oxf Engl. 2018;32:1098-103.

90. Martin WF, Correll CU, Weiden PJ, Jiang Y, Pathak S, DiPetrillo $\mathrm{L}$, et al. Mitigation of olanzapine-induced weight gain with samidorphan, an opioid antagonist: a randomized double-blind phase 2 study in patients with schizophrenia. Am J Psychiatry. 2019;176:457-67.

91. Moghimi Sarani E, Memari E, Anushiravani A, Mowla A. Is sitagliptin effective for modulating metabolic disturbances associated with olanzapine in schizophrenia patients? A doubleblind placebo-controlled clinical trial. J Clin Psychopharmacol. 2020;40:487-90.

92. Huang J, Hei G-R, Yang Y, Liu C-C, Xiao J-M, Long Y-J, et al. Increased appetite plays a key role in olanzapine-induced weight gain in first-episode schizophrenia patients. Front Pharmacol. 2020;11:739.

93. de Almeida V, Alexandrino GL, Aquino A, Gomes AF, Murgu $\mathrm{M}$, Dobrowolny H, et al. Changes in the blood plasma lipidome associated with effective or poor response to atypical antipsychotic treatments in schizophrenia patients. Prog Neuropsychopharmacol Biol Psychiatry. 2020;101:109945.

94. Potkin SG, Kunovac J, Silverman BL, Simmons A, Jiang Y, DiPetrillo L, et al. Efficacy and safety of a combination of olanzapine and samidorphan in adult patients with an acute exacerbation of schizophrenia: outcomes from the randomized, phase 3 ENLIGHTEN-1 study. J Clin Psychiatry. 2020;81.

95. Guan F, Zhang T, Han W, Zhu L, Ni T, Lin H, et al. Relationship of SNAP25 variants with schizophrenia and antipsychoticinduced weight change in large-scale schizophrenia patients. Schizophr Res. 2020;215:250-5.

96. Na K-S, Kim W-H, Jung H-Y, Ryu SG, Min KJ, Park K-C, et al. Relationship between inflammation and metabolic syndrome following treatment with paliperidone for schizophrenia. Prog Neuropsychopharmacol Biol Psychiatry. 2012;39:295-300.

97. Üçok A, Saka MC, Bilici M. Effects of paliperidone extended release on functioning level and symptoms of patients with recent onset schizophrenia: an open-label, single-arm, flexible-dose, 12-months follow-up study. Nord J Psychiatry. 2015;69:426-32. 
98. Chen C-Y, Tang T-C, Chen T-T, Bai YM, Tsai H-H, Chen $\mathrm{H}-\mathrm{L}$, et al. Efficacy, tolerability, and safety of oral paliperidone extended release in the treatment of schizophrenia: a 24-week, open-label, prospective switch study in different settings in Taiwan. Neuropsychiatr Dis Treat. 2018;14:725-32.

99. Chen C-H, Lin T-Y, Chen T-T, Chen VC-H, Lin N-C, Shao W-C, et al. A prospective study of glucose homeostasis in quetiapinetreated schizophrenic patients by using the intravenous glucose tolerance test. Prog Neuropsychopharmacol Biol Psychiatry. 2011;35:965-9.

100. Chue P, Malla A, Bouchard R-H, Lessard S, Ganesan S, Stip E, et al. The long-term clinical benefit and effectiveness of switching to once-daily quetiapine extended release in patients with schizophrenia. Curr Med Res Opin. 2013;29:227-39.

101. Lin C-H, Kuo C-C, Chou L-S, Chen Y-H, Chen C-C, Huang K-H, et al. A randomized, double-blind comparison of risperidone versus low-dose risperidone plus low-dose haloperidol in treating schizophrenia. J Clin Psychopharmacol. 2010;30:518-25.

102. De Hert M, Mittoux A, He Y, Peuskens J. Metabolic parameters in the short- and long-term treatment of schizophrenia with sertindole or risperidone. Eur Arch Psychiatry Clin Neurosci. 2011;261:231-9.

103. Xiang Y-T, Wang C-Y, Ungvari GS, Kreyenbuhl JA, Chiu HFK, Lai KYC, et al. Weight changes and their associations with demographic and clinical characteristics in risperidone maintenance treatment for schizophrenia. Pharmacopsychiatry. 2011;44:135-41.
104. Song X, Pang L, Feng Y, Fan X, Li X, Zhang W, Gao J, Zhang J, Nemani K, Zhang H, Lv L. Fat-mass and obesity-associated gene polymorphisms and weight gain after risperidone treatment in first episode schizophrenia. Behav Brain Funct. 2014 Oct 2;10(1):35. https://doi.org/10.1186/1744-9081-10-35.

105. Yuan X, Zhang P, Wang Y, Liu Y, Li X, Kumar BU, et al. Changes in metabolism and microbiota after 24-week risperidone treatment in drug naïve, normal weight patients with first episode schizophrenia. Schizophr Res. 2018;201:299-306.

106. Bresee LC, Majumdar SR, Patten SB, Johnson JA. Prevalence of cardiovascular risk factors and disease in people with schizophrenia: a population-based study. Schizophr Res. 2010;117:75-82.

107. Kelly DL, McMahon RP, Liu F, Love RC, Wehring HJ, Shim J-C, et al. Cardiovascular disease mortality in patients with chronic schizophrenia treated with clozapine: a retrospective cohort study. J Clin Psychiatry. 2010;71:304-11.

108. Correll CU, Kane JM. Ranking Antipsychotics for Efficacy and Safety in Schizophrenia. JAMA Psychiatry. 2020 Mar 1;77(3):225-6. https://doi.org/10.1001/jamapsychiatry.2019. 3377.

109. Cernea S, Dima L, Correll CU, Manu P. Pharmacological management of glucose dysregulation in patients treated with secondgeneration antipsychotics. Drugs. 2020;80:1763-81.

110. Bobes J, García-Portilla P, Sáiz PA, Bascarán T, Bousoño M. Quality of life measures in schizophrenia. Eur Psychiatry J Assoc Eur Psychiatr. 2005;20(Suppl 3):S313-7. 